\title{
Vaccination against Taenia solium Cysticercosis
}

\author{
Ana Flisser/ ${ }^{+}$, Marshall W Lightowlers* \\ Departamento de Microbiología y Parasitología, Facultad de Medicina, Universidad Nacional Autónoma de \\ México, 04510, México DF, México *Veterinary Clinical Centre, University of Melbourne, Werribee, \\ Victoria, Australia
}

Taenia solium is a parasite that causes human cysticercosis. Its life cycle includes the adult stage, the egg and the larval stage. Human cysticercosis is a disease related to underdevelopment, the main clinical manifestation is neurocysticercosis. Control measures include mass cestocidal treatment aimed to cure possible taeniosis cases. Although useful it has certain disadvantages, such as the generation of symptomatology in occult neurocysticercosis. Alternatively, health education has been shown to be highly effective since people become aware of the importance of human and porcine cysticercosis and the possibility of eliminating it. Nevertheless it has to be implemented by knowledgeable people. On the other hand, the life cycle can be controlled by avoiding swine cysticercosis. This review describes the studies performed to vaccinate pigs against $\mathrm{T}$. solium and indicate that short time perspectives are very encouraging for the production of an optimal vaccine.

Key words: cysticercosis - swine - Taenia solium - vaccination

Life cycle of Taenia solium - T. solium is a parasite that causes human cysticercosis. Its life cycle includes the adult stage, the egg and the larval stage. The adult parasite or tapeworm is lodged exclusively in the human intestine, it measures several meters long and is constituted by repetitive segments or proglottids. The last proglottids, which are shed with feces, contain approximately 50,000 eggs each. When a pig ingests human feces containing eggs and proglottids, eggs are released in the intestine, oncospheres (hexacanth embryos) hatch, activate, cross the intestinal wall and lodge in muscles, eyes and central nervous system, where they transform into cysticerci, which are the larval stage or metacestode. The cysticercus is a vesicle that measures around one centimeter in diameter, is whitish, semitransparent and has a spherical scolex inside. When a person eats rare or undercooked pork meat that contains cysticerci, the scolex protrudes, attaches to the intestinal wall and, 3 to 4 months later, a new adult parasite develops. Intestinal taeniosis is generally asymptomatic, as well as swine cysticercosis, that seemingly does not cause neurological problems to pigs. $T$. solium only causes disease to humans that harbor the larval stage, which occurs

\footnotetext{
${ }^{+}$Corresponding author. Fax: 525-6232466. E-mail: flisser@servidor.unam.mx

Received 11 July 2000

Accepted 17 October 2000
}

when we ingest $T$. solium eggs (Gemmell et al. 1983, Flisser 1988, 1994, Flisser et al. 1998).

Epidemiological data - Human cysticercosis is a disease related to underdevelopment. It is found in countries that lack adequate sanitary infrastructure and health education. This parasitic disease was identified in autopsy cases. Its importance became evident due to the high frequency of neurocysticercosis in neurological hospitals, where it is found in more than one of each 10 patients admitted and in one of each two late onset epilepsy cases diagnoses (Velasco-Suarez et al. 1982, Vazquez \& Sotelo 1992). The use of immunodiagnostic methods has shown that in rural as well as urban open population, anticysticercus antibodies can be found up to 15\% (Diaz-Camacho et al. 1991, Schantz et al. 1994, Correa et al. 1999, Garcia-Garcia et al. 2000). This information has allowed recognizing human cysticercosis as a public health problem in countries of Latin America, Africa and Asia, where, in the last two decades, different control measures have been evaluated (Gemmell et al. 1983, Flisser 1989, 1994, Flisser et al. 1998).

Mass cestocidal treatment, aimed to cure of possible taeniosis cases, has shown to be useful (Cruz et al. 1989, Sarti et al. 2000). This does have certain disadvantages, such as the generation of symptomatology in a case of occult neurocysticercosis during mass treatment with praziquantel in a rural population in México (Flisser et al. 1993). In another study the levels of swine cysticercosis returned to their original status just two years after 
mass treatment in a rural area in Ecuador (J Proaño, pers. commun.), due probably to the fact that no control was implemented to eliminate the source of tapeworm infection of human beings, that is pigs with cysticercosis. For these reasons it is considered more adequate to provide treatment to eliminate tapeworms only to those people previously identified or that have a high risk of being carriers.

Health education is highly effective as it was shown in the community intervened that became aware of the importance of human and porcine cysticercosis and the possibility of eliminating it (Sarti et al. 1997). Nevertheless health education must be provided by exprofesso well trained personnel and is still more effective if it is associated to identification and treatment of tapeworm carriers. Furthermore, it is necessary to elaborate and implement health education programs, which must be associated to improvement of sanitary infrastructure, elements that eliminated the presence of T. solium in Europe at the beginning of last century.

Vaccination - An alternative approach for the control of taeniosis and cysticercosis due to $T$. solium is the use of vaccines in pigs. Furthermore, an effective and safe vaccine against swine cysticercosis is mandatory for the evaluation of similar vaccines for human use.

Since there are many Taenia species that infect mammals, there are many studies in rodents, ovine and bovines that demonstrate that it is possible to acquire protection against cysticercosis by vaccination. In most studies crude antigens have been used which were obtained from oncospheres, cysticerci or tapeworms (Flisser et al. 1979, Lightowlers 1994). These studies have been relatively easy to perform since the different stages of the parasite (cysticerci and adults) develop in animals, thus it is feasible to maintain the infected hosts to be used according to experimental needs. Various degrees of protection have been reported; it has been demonstrated that living oncospheres and oncospheral antigens are the most effective (Flisser et al. 1979, Lightowlers 1994). Recently the use of recombinant proteins and DNA as vaccines against rodent, ovine and bovine cysticercosis has been used with high degrees of immunity (Johnson et al. 1989, Harrison et al. 1996, Lightowlers et al. 1996, Rosas et al. 1998, CruzRevilla et al. 2000).

In order to perform vaccination studies against $T$. solium there must be enough eggs accessible to challenge infected animals, eggs that can only be obtained from human beings with taeniosis. Probably this has been the greatest difficulty for performing such studies and the reason why there are so few publications in this respect. Recently an experimental model was established in chinchillas that allowed the reproduction of the complete life cycle of the parasite, since one chinchilla infected with cysticerci produced a gravid tapeworm, with which a pig was infected, developing 14 cysticerci (Maravilla et al. 1998). If this system can be reproduced reliably, an alternative for supply of $T$. solium eggs can be achieved.

In spite of the difficulty for obtaining $T$. solium eggs, there are published data that allow evaluating the usefulness of vaccination in pigs. Results obtained in various experiments performed in order to define if it is possible to protect swine against an oral challenge with $T$. solium eggs are summarized in the Table. As it can bee seen, different antigens have been used to immunize. In the first study performed, Herbert and Oberg (1974) used two doses of $T$. solium eggs, in the remaining studies, antigens were obtained as crude extracts from whole $T$. solium cysticerci (Molinari et al. 1983a), the scolices or their chromatographic peaks (Kumar et al. 1987, Nascimento et al. 1995), T. crassiceps vesicular fluid or the bands corresponding to proteins of 56, 66, and $74 \mathrm{kDa}$ from this fluid (Manoutcharian et al. 1996), secretions and excretions or crude extracts from T. solium oncospheres (Phatak \& Gaur 1990, Plancarte et al. 1999) and also T. ovis recombinant antigens (Plancarte et al. 1999). The number of eggs used for challenge of vaccinated or control animals fluctuated between 4,000 and 25,000. The last two columns of the Table show the results obtained, organized as average number of cysticerci established and percentage of establishment, calculated from the number of eggs used for challenge and the number of cysticerci counted at necropsy. Except for the results obtained by the groups of Nascimento and of Manoutcharian, establishment in non-vaccinated pigs ranged between $0.7 \%$ and $3.4 \%$ and in vaccinated groups between $0.02 \%$ and $0.2 \%$. A review of the literature yielded $1 \%$ of establishment in 255 non-vaccinated different mammal hosts infected with different species of Taenia and $0.3 \%$ in 927 vaccinated hosts (Flisser et al. 1979). The values shown in the Table are in the same range for nonvaccinated hosts but are lower in immunized hosts indicating that the efficacy of implantation of parasites in natural conditions is similar regardless host and Taenia species, in contrast implantation of cysticerci is lower in vaccinated pigs suggesting that swine immunization is quite successful. These data are of great importance because they also show that reproducibility of natural conditions of the infection is adequate, and thus, experimental data are valid. The work of Manoutcharian and colleagues (1996) yielded the highest protection; nevertheless the number of cysticerci established in control animals was the lowest in comparison with the other studies, while the work of Nascimento and colleagues (1995) had very high numbers of cysticerci established in non-vaccinated and also in immunized hosts. 
TABLE

Establishment of Taenia solium cysticerci in control pigs and in swine vaccinated with different antigens

\begin{tabular}{|c|c|c|c|c|c|}
\hline Author/Year & Vaccine & Pigs & Eggs & $\begin{array}{l}\text { Average } \\
\text { cysticerci }\end{array}$ & $\begin{array}{c}\% \\
\text { establishment }\end{array}$ \\
\hline Herbert/1974 & $\begin{array}{l}\text { None } \\
2 \text { doses eggs }\end{array}$ & $\begin{array}{l}3 \\
4\end{array}$ & $\begin{array}{l}4,300 \\
3,900\end{array}$ & $\begin{array}{r}146 \\
5\end{array}$ & $\begin{array}{l}3.4 \\
0.1\end{array}$ \\
\hline Molinari/1983 & $\begin{array}{l}\text { None } \\
\text { Crude extract }\end{array}$ & $\begin{array}{l}5 \\
6\end{array}$ & $\begin{array}{l}8,400 \\
8,400\end{array}$ & $\begin{array}{l}79 \\
12\end{array}$ & $\begin{array}{l}0.9 \\
0.1\end{array}$ \\
\hline Nascimento/1995 & $\begin{array}{l}\text { None } \\
\text { Scolex extract }\end{array}$ & $\begin{array}{l}4 \\
7\end{array}$ & $\begin{array}{l}10,000 \\
10,000\end{array}$ & $\begin{array}{l}926 \\
324\end{array}$ & $\begin{array}{l}9.3 \\
3.2\end{array}$ \\
\hline Manoutcharian/1996 & $\begin{array}{l}\text { None } \\
\text { Vesicular fluid } \\
\text { Gel bands }\end{array}$ & $\begin{array}{l}6 \\
7 \\
6\end{array}$ & $\begin{array}{l}10,000 \\
10,000 \\
10,000\end{array}$ & $\begin{array}{r}5 \\
2.5 \\
0.2\end{array}$ & $\begin{array}{l}0.05 \\
0.02 \\
0.002\end{array}$ \\
\hline Kumar/1987 & $\begin{array}{l}\text { None } \\
\text { Seph. 2nd peak } \\
\text { Seph. 1st peak }\end{array}$ & $\begin{array}{l}4 \\
4 \\
4\end{array}$ & $\begin{array}{l}15,000 \\
15,000 \\
15,000\end{array}$ & $\begin{array}{r}250 \\
56 \\
6\end{array}$ & $\begin{array}{l}1.7 \\
0.4 \\
0.04\end{array}$ \\
\hline Pathak/1990 & $\begin{array}{l}\text { None } \\
\text { Oncos. E/S }\end{array}$ & $\begin{array}{l}8 \\
8\end{array}$ & $\begin{array}{l}15,000 \\
15,000\end{array}$ & $\begin{array}{r}369 \\
19\end{array}$ & $\begin{array}{l}2.5 \\
0.1\end{array}$ \\
\hline Plancarte/1999 & $\begin{array}{l}\text { None } \\
\text { Recomb. T.ov. } \\
\text { Oncos. extract }\end{array}$ & $\begin{array}{l}5 \\
5 \\
5\end{array}$ & $\begin{array}{l}25,000 \\
25,000 \\
25,000\end{array}$ & $\begin{array}{r}172 \\
39 \\
16\end{array}$ & $\begin{array}{l}0.7 \\
0.2 \\
0.06\end{array}$ \\
\hline
\end{tabular}

Molinari and colleagues (1983b) informed that cysticerci of pigs with natural infections were infiltrated by eosinophils and had various degrees of necrosis after the pigs were vaccinated with a crude extract of $T$. solium cysticerci. A study performed in rural conditions with these same extract showed that 12 months after vaccinating thousands of pigs in several communities of an endemic area in Mexico, no pig was found with cysticercosis in hundreds of animals reviewed (Molinari et al. 1993). Even though the results are very encouraging, this vaccine corresponds to a crude extract, thus it has multiple components, some of which might have non-desirable effects, as has been shown with some antigens that facilitate the establishment of the infection, since, for example the efficiency of protection reported for the 220-205 $\mathrm{kDa}$ antigen obtained from $T$. crassiceps was of $-49.7 \%$ (Valdez et al. 1994).

Sciutto and colleagues (1990) demonstrated cross protection between $T$. solium and $T$. crassiceps, nevertheless the model of $T$. crassiceps, which is established in rodents by intraperitoneal injection of cysticerci, does not reflect the sort of protection that has to be induced against the ingestion of eggs and the passage of embryos through the intestinal wall and the circulation, as well as the establishment of larvae in target tissues. In $T$. solium cysticercosis, this same research group demonstrated recently that by vaccinating pigs with recombinant peptides in natural conditions, in a rural community in the state of Puebla, it was possible to reduce greatly this parasitic disease (pers. commun.).

The studies described above indicate that swine cysticercosis is feasible to be controlled by vaccination and that short time perspectives are very encouraging for the production of an optimal vaccine. Especially useful are recombinant proteins, since the trial performed showed high efficacy and the use of this type of proteins solve the problem of having unknown components in the mixture and the need of having cysticerci for the production of the vaccine. Probably the combination of targeted treatment of tapeworm carriers and vaccination of pigs, mainly in rural habitats, will enable to eradicate Taenia solium, and with it human neurocys-ticercosis.

\section{REFERENCES}

Correa D, Sarti E, Tapia-Romero T, Rico R, AlcántaraAnguiano I, Salgado A, Valdez L, Flisser A 1999. Antigens and antibodies in sera from human cases of epilepsy or taeniasis from an area of Mexico where Taenia solium cysticercosis is endemic. Ann Trop Med Parasitol 93: 69-74.

Cruz ME, Davis A, Dixon H, Pawlowski ZS, Proaño J 1989. Operational studies on the control of Taenia solium taeniasis/cysticercosis in Ecuador. Bull WHO 67: 401-407.

Cruz-Revilla C, Rosas G, Fragoso G, López-Casillas F, Toledo A, Larralde C, Sciutto E 2000. Taenia crassiceps cysticercosis: protective effect and immune response elicited by DNA immunization. $J$ Parasitol 86: 67-74. 
Diaz-Camacho S, Candil A, Suate V, Zazueta ML, Felix M, Lozano R, Willms K 1991. Epidemiological study and control of Taenia solium infections with praziquantel in a rural village of Mexico. Am J Trop Med Hyg 45: 522-531.

Flisser A 1988. Neurocysticercosis in Mexico. Parasitol Today 4: 131-137.

Flisser A 1994. Taeniasis and cysticercosis due to Taenia solium. In Tsieh Sun, Progress in Clinical Parasitology, Vol. 4, CRC Press Inc, Boca Raton, Florida, p. $77-116$.

Flisser A, Madrazo I, Delgado H 1998. Cisticercosis humana, El Manual Moderno, México DF, 176 pp.

Flisser A, Madrazo I, Plancarte A, Schantz PM, Allan J, Craig P, Sarti E 1993. Neurological symptoms in occult neurocysticercosis after a single taeniacidal dose of praziquantel. Lancet 342: 748 .

Flisser A, Pérez-Montfort R, Larralde C 1979. The immunology of human and animal cysticercosis. A review. Bull WHO 57:839-856.

García-García DL, Torres M, Correa D, Flisser A, SosaLechuga A, Velasco O, Meza-Lucas A, Plancarte A, Avila G, Tapia R, Aguilar L, Mandujano A, Alcántara I, Morales Z, Salcedo A, Manon ML, Valdespino JL 2000. Prevalence and risk of cysticercosis and taeniasis in an urban population of soldiers and their relatives. Am J Trop Med Hyg 61: 386-389.

Gemmell M, Matyas Z, Pawlowski Z, Soulsby EJL, Larralde C, Nelson GS, Rosicky B 1983. Guidelines for Surveillance, Prevention and Control of Taeniasis/Cysticercosis, VPH/83.49, WHO, 207 pp.

Harrison GBL, Heath DD, Dempster RP, Gaucci C, Newton SE, Cameron WG, Lawrence SB, Lightowlers MW, Rickard MD 1996. Identification and cDNA cloning of two novel low molecular weight host-protective antigens from Taenia ovis oncospheres. Int J Parasitol 26: 195-204.

Herbert IV, Oberg C 1974. Cysticercosis in pigs due to infection with Taenia solium Linnaeus, 1758. In EJL Soulsby, Parasitic Zoonosis, Academic Press, New York, p. 199-211.

Johnson KS, Harrison GBL, Lightowlers MW, O’Hoy KL, Dempster RP, Lawrence SB, Vinton JG, Heath DD, Rickard MD 1989. Vaccination against ovine cysticercosis using a defined recombinant antigen. Nature 338: 585-587.

Kumar D, Gaur SNS, Pathak ML 1987. Immunization of pigs against the cysticercus of Taenia solium using fractionated first and second peaks of cysticercus cellulosae scolex antigen. Indian J Anim Sci 57: 932935.

Lightowlers MW 1994. Vaccination against animal parasites. Vet Parasitol 54: 177-204.

Lightowlers MW, Rolfe R, Gaucci CG 1996. Taenia saginata: vaccination against cysticercosis in cattle with recombinant oncosphere antigens. Exp Parasitol 84: 330-338.

Manoutcharian K, Rosas G, Hernández M, Fragoso G, Aluja A, Villalobos N, Rodarte LF, Sciutto E 1996. Cysticercosis: identification and cloning of protective recombinant antigens. J Parasitol 82: 250-254.

Maravilla P, Avila G, Cabrera V, Aguilar L, Flisser A 1998. Comparative development of Taenia solium in experimental models. J Parasitol 84: 882-886.
Molinari JL, Meza R, Suarez B, Palacios S, Tato P, Retana A 1983a. Taenia solium: immunity in the hogs to the cysticercus. Exp Parasitol 55: 340-357.

Molinari JL, Meza R, Tato P 1983b. Taenia solium: cell reactions to the larva (Cysticercus cellulosae) in naturally parasitized, immunized hogs. Exp Parasitol 56: 327-338.

Molinari JL, Soto R, Tato P, Rodriguez D, Retana A, Sepulveda J, Palet A 1993. Immunization against porcine cysticercosis in an endemic area in Mexico: a field and laboratory study. Am J Trop Med Hyg 49: 502-512.

Nascimento E, Costa JO, Guimaraca MP, Tavares CAP 1995. Effective immune protection of pigs against cysticercosis. Vet Immunol Immunoparasitol 45: 127-137.

Pathak KML, Gaur SNS 1990. Immunization of pigs with culture antigens of Taenia solium. Vet Parasitol 34: 353-356.

Plancarte A, Flisser A, Gaucci CG, Lightowlers MW 1999. Vaccination against Taenia solium cysticercosis in pigs using native and recombinant oncosphere antigens. Intl J Parasitol 29: 643-647.

Rosas G, Cruz-Revilla G, Fragoso G, López-Casillas F, Pérez A, Bonilla MA, Rosales R, Sciutto E 1998. Taenia crassiceps cysticercosis: humoral immune response and protection elicited by DNA immunization. J Parasitol 84: 516-523.

Sarti E, Flisser A, Schantz PM, Gleizer M, Loya M, Plancarte A, Avila G, Allan J, Craig P, Bronfman M, Wijeyaratne P 1997. Development and evaluation of a health education intervention against Taenia solium in a rural community in Mexico. Am J Trop Med Hyg 56: 127-132.

Sarti E, Schantz PM, Avila G, Ambrosio J, MedinaSantillán R, Flisser A 2000. Mass treatment against human taeniasis for the control of cysticercosis: a population-based intervention study. Trans $R$ Soc Trop Med Hyg 94: 85-89.

Schantz PM, Sarti E, Plancarte A, Wilson M, Criales JL, Roberts J, Flisser A 1994. Community-based investigations of cysticercosis due to Taenia solium: comparison of serological screening tests and clinical findings in two populations in Mexico. Clin Infect Dis 186: 879-885.

Sciutto E, Fragoso G, Trueba L, Lemus D, Montoya RM, Diaz ML, Govezensky T, Lomeli C, Tapia H, Larralde C 1990. Cysticercosis vaccine: cross protecting immunity with $T$. solium antigens against experimental murine $T$. crassiceps cysticercosis. Parasite Immunol 12: 687-696.

Valdez F, Hernández M, Govezensky T, Fragoso G, Sciutto E 1994. Immunization against Taenia crassiceps cysticercosis: identification of the most promising antigens in the induction of protective immunity. J Parasitol 80: 931-936.

Vazquez V, Sotelo J 1992. The course of seizures after treatment of cerebral cysticercosis. NEJM 327: 696701.

Velasco-Suarez M, Bravo MA, Quirasco F 1982. Human cysticercosis: medical-social implications and economic impact. In A Flisser, K Willms, JP Laclette, C Larralde, C Ridaura, F Beltran (eds), Cysticercosis. Present State of Knowledge and Perspectives, Academic Press, New York, p. 47-51. 